\title{
Case Studies in U. S. Distance Education: Implications for Ghana's Under-Served High Schools
}

\author{
Gabriel Kofi Boahen Nsiah \\ Department of Education, School of Development Studies, Education and Health Sciences, Valley View \\ University, Accra, Ghana. \\ Email: \{gabrielnsiah, nsiahgabriel\}@gmail.com \\ Received June $15^{\text {th }}$, 2011; revised July $18^{\text {th }}$, 2011; accepted July 31 ${ }^{\text {st }}, 2011$.
}

\begin{abstract}
Ghana, like many other nations in recent years, has made education a top priority for national development. Despite newly developed policies, however, there remains a significant quality gap among high schools; due largely to an inequitable ratio of government's educational spending by geographic area. While most urban schools flourish with better funding and more resources, many rural schools are substandard due to funding inequity, inadequate infrastructure, and lack of logistical support, material input, and qualified teachers. These problems call for attention and resolution and distance education is considered a panacea to these problems. To achieve this objective, three distance education sites/cases - two parochial schools and one large state-supported public school were studied. Using a variety of data collection interview methods-video conferencing, Skype, face-to-face conversations, and e-mail-interviews were conducted with individuals representing various roles at the three case study sites in the United States: teachers, principals, local and district administrators, and technical and program directors. Effective and ineffective practices at these focus sites provided contextual referencing for future program development/replication in Ghana. Interviews revealed many common issues and themes for success in facilities/program development, program management, and instructional delivery. Recommendations and a model for online distributed education emerged to aid in addressing Ghana's educational needs. The study findings can inform other systems, nationally and internationally, though the study specifically emphasized concerns in Ghana-where quality education is needed to better prepare under-served school populations for higher education and for further contribution to the development and prosperity of that nation.
\end{abstract}

Keywords: Distance Education, Technology, Privileged, Under-Served, Interactive

\section{Introduction}

Today, more than ever before in human history, the wealthor poverty-of nations depends on the quality of higher education. Those with a larger repertoire of skills and a greater capacity for learning can look forward to lifetimes of unprecedented economic fulfillment. But in the coming decades the poorly educated face little better than the dreary prospects of lives of quiet desperation (Gillis, 1999: p. 18).

Education plays a significant role in shaping a developing nation, and the proliferation of Internet-based educational opportunities has expanded distance learning modalities to all parts of the globe. This study explores the potential for interactive distance educational technology to provide quality education that bridges the educational gap between privileged and under-served high schools in Ghana, West Africa, using three model programs based in the United States as points of comparison.

The quality of a nation is judged by the quality of its human resources, and the quality of human resources is maximized through education (Harber, 2010). Education provides the knowledge and skills needed to steer the developmental wheels of a nation to its destination of prosperity by improving the lives of individuals and enriching the wider society (Harber, 2010; Phillips \& Schweisfurth, 2007; Yusuf, 2006). Educational attainment is positively correlated with increased wages and productivity, which make both individuals and countries richer. Beyond the monetary benefits, education also introduces people to an enhanced "life of the mind," offering cultural and political benefits, while encouraging independence and initiative, both of which are valuable commodities in the knowledge society (The Task Force, 2000: p. 40).

Education increases employment opportunities and earnings, and allows even the poor within a society an opportunity to develop knowledge and skills (The Task Force, 2000; Tomasi, 2002). A well-trained workforce contributes to rising tax streams, improved institutional capital, and affordability of better healthcare that can prolong lives and encourage sustainable economic growth (The Task Force, 2000).

\section{Problem Statement}

The problem this study seeks to address is to bridge the gap in educational attainment and opportunity that exists between privileged secondary education settings and those who come from under-served systems by considering the role of distance education in improving the educational status of under-served students. In so doing, it is hoped that narrowing the gap can afford more students opportunities for advanced education, and that both individuals and society as a whole will benefit economically and socially.

\section{Purpose Statement}

The United States has more years of experience in the use of interactive educational technology than does the country of Ghana (Freed, 2003). Studying successful and unsuccessful interactive distance education technology programs in the United States can contribute to a model for quality distance education that can be used to address disparities in Ghanaian education. Therefore, the purpose of this qualitative case study is to explore ways and means that interactive distance education in 
the United States has or has not enhanced learning for students, and to use these experiences as a basis for developing a model that suits the needs of under-served schools in Ghana. Doing this will contribute to understanding that can be helpful in dealing with the uneven playing field of education in Ghana.

\section{Research Questions}

This study is guided by the following research questions:

1) How is interactive distance educational technology used to provide education for selected high schools in the United States?

2) What is the perceived level of program effectiveness among selected U. S. high schools currently using interactive distance educational technology?

3) What are underlying factors responsible for success in the use of interactive distance educational technology in selected high schools in the United States?

4) How can specific principles/themes from this study of certain U. S. distance education programs inform the development of potential similar distributed education in Ghana, Africa?

\section{Methodology}

\section{Study Participants}

Participants represented various disciplines within the field of education. This provided a wide variety in perspective. Participants included a superintendent of schools, a technical director, an environmental science teacher, a math and science teacher, an administrative supervisor, curriculum developers, a program developer, a program director, and a vice president for global services and esolutions manager.

\section{Data Collection}

\section{Observation}

Qualitative research is field focused, and data are collected by researchers in the field at the site where participants experience the issue or problem under study (Creswell, 2007: p. 37; see also Eisner, 1991). Data collection occurred at all three case study sites. This allowed for classroom and facilities observations. Additionally, follow-up interviews were conducted by phone and email when clarification was necessary.

\section{Access to Sites and Individuals}

Gaining access to sites and individuals involved several steps. The research plan was submitted to the university human subjects review board (Cresswell, 2007: p. 123), and approval from the Institutional Review Board (IRB) was acquired prior to beginning formal data collection. Upon receiving approval from the IRB, I travelled to a state in the southeastern part of United States to begin collecting data. This southeastern location became the center point for my data collection because two of the cases were situated in this area.

Specific arrangements were established with participants prior to travel to conduct the interviews through an e-mail invitation to participate in the study. Eight of the thirteen (13) participants were prompt in responding to invitational e-mails and phone calls to participate. Of the remaining five individuals, three were contacted at the initial stages but they failed to respond to either e-mails or phone calls. However, while onsite in the southeast, the opportunity to interview them materialized. Two names were added to list of available interviewees while on the grounds collecting data, thus expanding the participant pool. Prior to arriving at the schools, documents were sent to each participant. Letters and copies of the interview questions were sent electronically and by mail to each participant. This was done to help each participant better prepare their thoughts for the interview.

Data collection lasted for eight days at the southeastern site-February 19-27, 2009. Four of the interviews were conducted via video conferencing, one via Skype, and the rest were conducted face-to-face. Prior to starting each interview, participants were presented with a confidentiality agreement letter, which each participant read and signed. To establish a comfortable atmosphere and to reduce anxiety, each interview started with a personal question as to what motivated the interviewee to get involved in distance education. Interviews were recorded with two digital audio recorders to provide backup if necessary. A camera and camcorder were also used to collect the data. Only the researcher has access to these data.

Those interviewed included: program directors, administrators, technical director, curriculum developers, a superintendent of schools, and distance educators. Thirteen categories of questions guided the interviews, which addressed the research questions and theoretical perspective of the research. Interview questions involved:

1) Initial organization

2) Funding and sustainability

3) Technology of delivery

4) Administration and staffing

5) Program definition

6) Recruitment of students

7) Instructional efficacy

8) Assessment methods

9) Students performance

10) Faculty feedback

11) Constituency response

12) Program marketing

13) Program efficacy

Two weeks after the interviews were concluded, participants were sent a thank you letter. This letter informed participants that they would be contacted for clarification should there be need to do so.

\section{Data Collection Description}

The first interview took place on February 20, 2009. After the interview, the director of PSA (pseudonym) program invited me to his school office. He provided a tour through the facility, and we then settled in a room where he holds meetings with his staff. An informal conversation began at this point as he briefed me regarding his program. This conversation was not part of the formal interview, but it provided a general overview as to how he runs the program. These interactions lasted for almost three hours. The conversation was helpful, as it allowed me to reflect on my research process and to make some adjustments to the interview questions.

Four interviews were conducted via synchronous video conferencing technology with two participants in Tennessee, one in Washington state and the other participant living in Florida. PSA teachers instruct through this medium and broadcast from their homes, which serve as their offices. They have students who sit in regular classrooms and home school- students. All tune in during the class period and are able to see each other on their computer screen/monitor. The teacher appears large on the television screen, while images of the students in the participating schools appear in smaller frames on the screen through videoconferencing technology. If a student wants to 
answer or ask a question, he or she does so by pushing a button on a controller connected to the video camera. The student's image then appears large on the screen, and the student can speak to the other participants.

Nine of the participants were also interviewed on a one-onone basis in offices and on school premises. One participant was interviewed at her apartment. The last interview was conducted via Skype (a software application with capability for allowing users to make calls over the Internet along with the feature of two-way video imaging).

\section{Data Analysis}

Essentially, qualitative data analysis involves defining, categorizing, theorizing, explaining, exploring and mapping vast quantities of data (Huberman \& Miles, 2002). As a researcher, I listened to the audio recordings of the interviews several times to gain an indepth comprehension of the data. The interviews were transcribed verbatim. These transcribed data were studied meticulously along with other documents obtained from the field, such as school records, brochures, field notes, etc. Data analysis strategies such as sketching ideas, taking notes, writing margin notes, highlighting certain information, identifying codes, and reducing codes to categories, were applied in analysis of the contents of the data (Creswell, 2007; Davies, 2007).

Categories emerged through the use of a data analysis matrix listing the research questions and interview questions. These categories came forward from the interview questions as a result of building a logical chain of evidence through identification of patterns of uniformities in line with the research questions that framed the study (Creswell, 2007; Davies, 2007). Thus, categories were organized to coincide with the research questions, the literature review, and the overall purpose of the research (Charmaz, 2003; Flick, 2007; Giorgi \& Giorgi, 2003; Maso, 2001).

A second matrix was developed to organize interview question responses from each of the three case studies. After each category, interview questions were listed and data from the three cases were identified and aligned. This matrix allowed corresponding evidence to be seen.

\section{Results}

\section{Research Question 1}

Research question 1 asked, How is interactive distance educational technology used to provide education for selected high schools in the United States? The purpose of this research question was to study distance education programs in the U.S. as potential models for such programs in Ghana, Africa. In view of this, how the studied cases use technology to provide education was of interest. The technologies employed by the studied cases in their program delivery program provide examples of strategies, successes and failures. From this question, four related categories of information were seminal: Technology of delivery, program development, technology reliability, and teacher-media relations.

Technology of delivery. The study findings indicated that distance education is about technology. All three schools leverage interactive technologies to reach students and facilitate interactions between teachers and students. Examples of delivery media used in the case schools were: Real-time interactive videoconferences, two-way desktop video-conferencing that delivered lessons via the Internet, and asynchronous Web-based courses, which require the use of computers with Internet access.

The use of different delivery technologies underscores that distance education can be offered through a variety of media. The choice of an appropriate medium will be informed by the availability of technology and finances.

Program development. Program development must start with an assessment of individual needs. As with the three schools studied, the type of distance education program developed will be based on the identified needs of the targeted area. Another important aspect of program development is administration. In the schools studied, several different roles emerged. Administrators were responsible for sustainability and online programming. Schools also followed different models of administration, with some following a business-oriented model and others following a more traditional academic model.

Notably, the three programs studied were started by individuals with little or no background in technology-just passion for innovation. To address this, all new hires were required to have strong technological backgrounds. All programs also emphasized the importance of providing professional development for teachers.

Technology reliability. Technology reliability is crucial to operating distance education programs. Each school studied discussed the preventive and back-up measures they have in place to deal with the inevitable failures of technology, whether they are temporary or permanent failures. Schools had systems in place to repair their technology and provide students with alternative services when regular systems were down.

Each site employed preventative measures to ensure reliable and consistent technological performance. These included backup systems and servers, procedures to ensure proper configuration of their technology, vendor contracts to address any technical challenges, a separate technology department which included a proprietary management system, help desk, recovery center, and scheduled maintenance. When technological failures affect student communication, schools provided prerecorded classes, offered toll-free numbers for technical support, and allowed students to reset exams in the wake of any technical problem. Given the critical nature of such planning, it will be important for Ghana to establish similar precautionary measures to handle technical issues.

Teacher-media relations. Interviews revealed mixed reactions among teachers regarding media and its role in teaching. Teachers expressed excitement about the numerous opportunities technology offers in this kind of educational environment. They also admitted some apprehension about the use of technology, particularly among older teachers. Technical support and sharing of ideas among teachers were used as ways to ease tension in online instructors.

While most teachers tend to fall back on instructional methods used in traditional classrooms, interviewees also expressed the belief that open-mindedness and willingness drive interest for teaching in this kind of environment. Further, once teachers begin to master technology, they tend to prefer this instructional medium. Thus, falling back on old instructional methods is seen as a call for training in teaching in an education environment. No matter how experienced one may be, training is vital when implementing a new program such as distance learning.

\section{Research Question 2}

The second research question that guided this study asked, 
What is the perceived level of program effectiveness among selected U.S. high schools currently using interactive distance educational technology? As the purpose of this research is to make recommendations for the introduction of similar programming in Ghana, the effectiveness of programs delivered through a medium similar to what is proposed is pertinent. Therefore, the perceived level of program effectiveness among selected U.S. high schools currently using interactive distance educational technology, as explored by the three cases that comprise this study, became one of the focus questions of this research.

In line with the above question, categories related to program effectiveness, student/parental satisfaction, importance of interaction, class size, and student assessment were identified through the data analysis and are discussed below:

Program effectiveness. Program effectiveness is discussed in three separate themes: Overall effectiveness, cost effectiveness, and level of funding. Each program had different standards by which it measured its own overall effectiveness. For one school, effectiveness was measured by profitability and student enrollment. Another measured effectiveness by college acceptance rates. The final school used growth in student enrollment, academic performance, and receipt of awards to gauge effectiveness.

Programs are also concerned with their degree of cost effectiveness. This, again, is a subjective measure. In this study, cost effectiveness was measured in terms of technology costs, the ability to cover operation costs with tuition revenue, and the financial advantages of running a virtual program compared with a brick-and-mortar campus.

Sources of funding are an important consideration for set-up costs and sustainability. In this study, initial funding was provided through individual and organizational gifts and grant monies. Two of the schools sustain their financial effectiveness through tuition, state funding, organizational support, and product licensing. One school was unable to secure sustained funding and is no longer operational.

Student/parental satisfaction. Student/parental satisfaction was another important variable identified through the study. Successful distance learning education requires high levels of satisfaction among students and their parents. While satisfaction is individually determined by each program, some common factors included students' performance and their ability to attend college.

Interaction. The interaction between students and teachers is critical to success in the distance environment. Tools commonly used to facilitate interaction include: e-mail, text messaging, instant messaging, telephone, scanner, Webinar, and Elluminate. Each of these tools provides students and teachers with flexible approaches to interaction as they address instructtional and interpersonal needs. The importance of interaction is recognized in both traditional and online education.

All three institutions acknowledge the importance of service learning, and each made provisions for socialization and service learning in their various programs. Service learning provides students an opportunity to socialize within a semi-structured environment and work toward a common goal. This serves the dual purpose of both socializing and educating the students, while giving students an opportunity to donate their time to beneficial causes and learn about citizenship and personal responsibility.

Our world is a world of connection. Encouraging socialization will help students broaden their social network. With broad social networks, students stand to benefit from one another.
Their future success may depend on the social connections they make in school.

Class size. Class size is a matter of considerable importance in distance education - in either synchronous or asynchronous programs - as determined by the participants of this study. Interviewees admitted that teaching online is different from teaching in traditional classroom. With distance learning, there is a great deal of after-classroom work. Teachers respond to students' e-mails to answer questions or clarify understanding on issues, and students have more access to instructors via this medium. In view of this, the amount of time necessary to address the needs of each student rises in significance, and with this, class size also becomes a matter of significance.

The question as to what constitutes an ideal class size brought forward various answers across the three cases, though there was general agreement between two schools. One case suggested an optimal class size of 15 - 30; another case suggested a class size of 18 - 30, while the third case suggested a class size between 125 - 150. These very different answers indicated that in the distance learning environment, one size does not fit all. Class size depends on the nature of the class and program. All cases used different technology and ran synchronous and/or asynchronous programs with differing numbers in class size.

Assessment of student learning. The three cases involved in this study made assessment a vital part of their programs. A variety of assessments methods were used at the various sites in this study, but the most common means, as con- firmed by this research were through portfolio, true or false questions, multiple choice questions and projects.

All three sites acknowledged plagiarism and cheating as issues. For combating plagiarism and cheating, the three sites highlighted the need for teacher to know each student's level of writing against commonly available papers on the Internet. They suggested the use of online services such as "www.turnitin.com" as way of handling the practice. Additional strategies to prevent and address academic dishonesty also emerged from the interviews, such as knowing students level of writing and conducting oral interviews on a student's work. Given the substantial effort schools put into dealing with issues of academic dishonesty, it is evident that including this consideration in the plan for the Ghana model of distance education will be critical.

\section{Research Question 3}

Research Question 3 asked, What are the underlying is- sues responsible for success in the use of interactive distance educational technology in three selected high schools in the United States? The purpose of this research is to help Ghana improve its educational system by establishing a plan to deliver secondary education at a distance using interactive technologies. To assure that planning for a distance education program in Ghana is optimized for success, identifying issues that have supported success in other programs is useful exercise. This research question seeks to gather such information for consideration in the creation of plan for Ghana.

From the above question, three major categories of issues emerged during the interviews. The following sections address those three main issues involved in this research question: success issues, failure issues, and sustainability.

Success issues. Success, according to the study data, is a combination of human and capital resources working together to best serve the student. Participants offered the following as 
necessary for success: Reliable technology, quality instructors, qualified site facilitators, effective and collaborative support staff, and positive character traits shared among all staff, such as patience, graciousness, tenaciousness, resilience, flexibility and creativity.

Failure issues. The studied cases expressed several factors that put their programs at risk for failure. These included: Providing instruction at the appropriate level, the lack of skillful ways to address student needs, lack of good site facilitators, conflicting mindsets among teachers, lack of good communication, unmotivated students, lack of parental involvement and support, misconceptions about distance education, and technology failures.

Sustainability. Sustainability requires sound budgeting, making data-driven decisions, maximizing productivity, and continuous quality improvement in the educational product. Another issue of sustainability highlighted by participants is making data-driven decisions. Continuous quality improvement was another theme highlighted in this study.

All three groups highlighted the importance of flexibility in maintaining the success of their programs. As student needs change and technology evolves, it is incumbent on distance education programs to remain responsive to these changes. Failure to do so will likely leave a program behind.

Sustainability, according to the data analysis, stems from maximizing the identified issues for success and avoiding the pitfalls of failure. Maximizing productivity, improving program quality and maintaining flexibility are requisite to program sustainability.

\section{Research Question 4}

The previous sections focused on the results of research questions one through three and investigated the use of technology, program effectiveness, and issues of success. This section examines the results from research question 4: How can specific principles/themes from this study of certain U.S. distance education programs inform the development of potential similar distributed education in Ghana, Africa? The purpose of this research question, and the purpose of the study as a whole, was to identify strategies for using best practices established in U.S.-based distance education pro- grams as a basis for developing a model for Ghana. This section therefore focuses on the salient administrative issues that have to be considered in creating a distance education program in Ghana, as informed by the interviews that comprised this study and the themes that evolved from those interviews.

The themes and principles identified in the previous section provide a framework for developing a distance learning program for Ghana. This framework must be considered in concert with Ghana's readiness and ability to embrace distance learning. The following section outlines the existing technological infrastructure and proposed changes.

\section{Proposed Model for Ghana}

The interviews that provided the data for this study offered rich insight into issues that promote success in secondary distance education, as well as issues that can threaten the expansion and sustainability of programs. This model is grounded in the findings of this research. It applies the derived principles/ themes to the practical realities of infrastructure, funding, and politics in Ghana today. The proposed model serves as a basis for future educational planning with the hope that it can con- tribute to bridging the educational gap between privileged and under-served high schools in Ghana.

Despite Ghana's efforts to establish a competitive advantage in information technology, Internet accessibility is not a reality everywhere in Ghana. In light of this, the model proposed reflects the reality on the ground. A basic model for discussing development of a limited distance learning program is offered. At this time, Ghana does not have adequate technologies available outside of large metropolitan areas. Therefore, it is worth mentioning that some of the principles and themes applied in the development of this model are based on issues pertinent to the Ghanaian system while some are not.

The proposed model is a centralized high-school curriculum delivered on televisions or computers screens through DVDs and/or flash drives and distributed to under-served schools around the country. The curriculum will be delivered by outstanding Ghanaian teachers, following the core curriculum mandated by the Ghanaian government. On-site facilitators will be present in the classroom as lessons are delivered on the television or computer screen, depending on available resources. The government of Ghana, Non-Governmental Organizations (NGOs), and philanthropic organizations and individuals are expected to fund the program. This model is an exciting step forward in the effort to provide consistent, quality education for all Ghanaian children, providing a more level playing field for access to higher education and economic security.

What follows is an outline of the proposed distance education model for Ghana developed around the principles and themes derived from the current study. The model is described in six core topic areas: Program development, delivery medium, funding, instructional personnel, site facilitator and evaluation.

\section{Program Development}

Program development must start with a need assessment. The identified needs are lack of infrastructures, lack of logistics, and lack of qualified teachers. As resources are limited and this is only the first step toward educational reform, this model will focus primarily on the lack of qualified teachers in many under-served areas of the country. Many secondary students in Ghana face considerable disparity in educational resources. Those students living in under-served areas do not have adequate resources needed to achieve academic success and go on to college. The provision of centralized educational curriculums, designed and taught by Ghana's brightest and best educators, represents significant progress toward the goal of equitable and quality education.

A team of well-qualified educators, administrators, instructtors, superintendents of schools, and the Ghana government will be the stakeholders in the program development and operation. The Ghana Education Service (GES) operates under the Minister of Education, Science and Sports and provides oversight for elementary and high school education. Well-qualified teachers in individual subject areas would be contacted and contracted through GES to build curricula that best leverages the affordances of interactive distance education. These teachers would present lessons in their subject areas in line with the approved syllabi of the GES. The lessons would be videotaped and burned onto DVDs and/or flash drives for distribution to schools in under-served environments. Students in these schools would have the ability to watch the lessons in class using a DVD player and television screen. The availability of electricity supply in cities and towns where high schools are located would make the viewing of the lessons through video 
player and television screens possible. This would give under-served schools the opportunity to enjoy quality lessons from well-qualified teachers.

The curricula would need to be in accordance with the approved syllabi of the Ghana Education Service. Collaboration with GES will help ensure that curricula meet the government content and quality standards for secondary education.

The results of this study reinforce the importance of interaction. For interaction such as questions and answers after watching the lesson or presentation, under-served schools would have on-site facilitators to help answer questions for students on-site, and challenging questions beyond the facilitator's knowledge would be referred to the educator or curriculum author through e-mail, text, telephone, or other available communication technology.

Another important consideration in any distance education program is the role of community and service learning. Formation of knowledge, according to social constructivist theory, depends on one's social environment and service learning. According to Caviness (2007: p. 27) the social dimension of education "is a valuable part of holistic education". The proposed model will provide social opportunities for students by going on retreats and using electronic features such as chat, e-mail, blogs, wiki and students clubs. They will render services to the community by caring for the aged in nursing homes and the sick in hospitals. They also engaged in service learning through collaborative assignment. Socialization and service learning is recommended in the curriculum to bridge the existing disparity between privileged and under-served schools in Ghana. Socialization and service learning programs, such as serving in public places like hospitals, museum, zoo, historical buildings, will be introduced.

\section{Delivery Medium}

Technology provides the backbone for distance education programs. With the widespread availability of communication media, students and teachers in different geographic locations can interact through technology. The Internet is the most common delivery medium for current-day distance education programs. Although the future of Ghanaian technology is promising, most areas, particularly those with lower incomes, do not have reliable Internet connections. Given this reality, a more common and readily available delivery medium is proposed. Most school-aged Ghanaian children have access to television sets with DVD players and many have access to personal computers with Universal Serial Bus (USB) ports. The proposed distance education model would use these as delivery media. Curricula would be disseminated on DVDs or flash drives, for playback on televisions or computer. Interaction between instructors and students would occur via telephone, e-mail, text messaging, or other available technology. Each classroom participating in the distance education would require the following equipment for curriculum delivery: Television monitors, DVD players or USB ports, and telephone lines or cables.

The production and development of the course materials would take place either in a production studio or regular classroom. On the way to achieving the model state of technology diffusion, an intermediate model could provide a studio for recording content-lessons prepared by qualified teachers in their subject areas with particular attention to interactivity and with the fully leveraged benefits of distance education. These lessons could be videotaped and uploaded onto a site accessible by schools in under-served environments. Students in these schools could have access to recordings-CDs or otherwisecontaining the lessons along with availability of equipment to project onto a television and to interact with the lessons. This would provide under-served schools with opportunity to enjoy quality lessons from well-qualified teachers. With the current state of Ghana's technology system, this is a possibility for future programming. The focus of this study has been a more realistic proposal for more immediate initiation. As a result, more realistic and basic forms of recording in regular classroom is proposed to meet the immediate educational needs of underserved areas.

To provide delivery of the content to the students this basic model would require computers, telephone lines or cables, camcorders for recording of classes, and the ability to distribute courses and content. Contents would be prepared in advance to ensure that schools received the materials in a timely manner. Distributions to sites without Internet capability for downloading would be made through regular mail or could be available for pick up at educational offices within the district.

Since this study will not rely on the Internet as its initial delivery medium, a full technical team will not be need. However, technical personnel would be trained to support teachers to develop the content. Their job would be ensuring quality production through proper recordings, editing the content, posting the content on the web, burning content on DVDs and flash drives, and providing technical support for on-site facilitators. Technical support for students would be provided by the individual schools. Students will receive basic training to operate the television set with the DVD player.

Program developers should pursue collaborative partnerships with existing educational organizations, such as the New Partnership for Africa Development (NEPAD). NEPAD is currently establishing science centers throughout Ghana and may be able to provide some educational content and classes for the distance learning program. Partnerships such as this can greatly enhance the educational experience.

\section{Funding}

Programs cannot be sustainable without securing initial and ongoing funding. One of the studied cases ultimately closed because they lacked ongoing funding. Initial planning must include all anticipated start-up and ongoing costs and expenses. The recommendations provided do not include financial support for costs related to infrastructure, teacher salaries, or curriculum development — which will be considerable.

The government of Ghana, NGOs, philanthropic organizations and individuals are expected to provide the majority of start-up funding. A proposal, built on this study, would be sent to the Ghana government and relevant NGOs and philanthropists in pursuit of grants and other funding to begin operations. Some of the considered NGOs are Volunteer Partnership for West Africa, Savannah Education Trust Fund, PAAJAF Foundation, and the Cheerful Heart Foundation. However, these resources must be considered temporary. Start-up monies must be replaced by more sustainable and reliable sources of funding, such as tuition. Other possible sources of revenue might include selling the curriculum materials to students. Beside the above, program developers will pursue partnerships with universities and colleges who might have the resourcesboth human and financial- to develop the curriculum and present the lessons on DVDs and flash drives. Universities are often resource rich and able to provide support for all aspects of a project such as the proposed model. 


\section{Instructional Personnel}

Well-qualified educators are key to any successful distance learning program. Recruitment, hiring, and retention of wellqualified educators is essential to the proposed model. These educators will provide instruction and consultation to site facilitators and students alike. Additionally, distance learning programs rely on competent and qualified site facilitators. This unique role is designed to be intellectual, social, managerial, and technical. The facilitator of the class will help students with questions and answers while referring difficult questions to the content developer through telephone, text, e-mail and other means of communication available to the facilitator/class.

The Ghana Education Service (GES) is the institution that provides educational services to the nation's educational institutions. Recruitment efforts would include contacting the GES for recommendations and announcements to all qualified educators regarding open positions. Once the program director identifies a group of qualified candidates, the selection committee would interview and select candidates. Qualified candidates will have exemplified excellence in their courses through effective instruction resulting into national academic excellence.

Professional development will be an important part of the proposed model. Efforts will be made to provide relevant and current trainings for all levels of staff from doctoral-level educators to paraprofessionals providing administrative support. In concert with incentive programs, these professional development seminars will be part of the retention efforts.

\section{Site Facilitator}

Site facilitators were noted throughout this study as being crucial to the success of distance learning. Site facilitators perform four main functions-intellectual, social, managerial, and technical. As the class facilitator, they help students with questions and answers. Any questions beyond their scope of knowledge are referred to the content developer through telephone or other available means of communication.

As this is a new role, site facilitators likely will require onthe-job training. Like the content developers, a resource person will provide training to site facilitators. Both site facilitators and students will receive training to trouble shoot any technical issues that arise.

\section{Evaluation}

The purpose of this study was to improve the quality of education for under-served schools. In order to ensure quality instruction is being offered and learning being enhanced, progressive data will be kept on instruction and learning on computer. Data will be kept on students test scores to determine any effect as a result of the program. Both students and parents will assess the effectiveness of instruction at the end of every school term. They will be presented with evaluation forms at the end of every school term to evaluate the program. This will give them the opportunity to evaluate the program and express their level of satisfaction. Improvement measures will be enforced as data determine an area of weakness.

\section{Conclusion and Recommendations}

The primary purpose of this research was to examine successful and unsuccessful distance learning programs and use these data to inform the development of a distance learning program in Ghana. The three schools studied successfully started and ran their programs for several years. Funding was different in each school, and two of the schools were able to secure sustainable funding. One was unable to continue because they had depended on a single funding source and did not develop new streams of money. The loss of funding suggests the importance of securing initial and sustainable funding when developing a distance learning program.

An examination of the themes reveals that it is not one single issue that determines the success of a program, but rather a multitude of issues including program development, attention to technology, hiring and retaining qualified staff, implementing sound assessment, and securing initial and continuing funding. Training teachers and students to be successful is a complex but necessary component of beginning and maintaining a successful distance learning program.

The transferability of the ideas and processes for running distance learning in Ghana is not as simple as copying a successful program from a different country. Although much can be learned from the three sites studied, additional study and planning will be necessary before beginning a program in Ghana. This study provides much needed information about the complexities of the task. To begin such a task requires much indepth planning, interaction, and commitment on the part of the educators in Ghana. The energy, desire and vision of the Ghanaian people, administrative personnel, and policy makers, will be crucial in the development of a successful program. Without the support of the Ghanaian people as a whole and those identified to develop distance learning in particular, a distance learning program will inevitably fail. Links with parents and educators will also be an important part of any successful program in Ghana. In the U.S., distance learning programs that were part of this study, parent commitment and involvement were essential to the well-being of all three programs.

Six core principles emerged for consideration in the development of a distance learning program in Ghana: Program development, delivery medium, funding, instructional personnel, site facilitator and evaluation.

\section{Recommendations}

The following recommendations are for schools offering distance education programs in the United States and Ghana respectively. They could apply to other distance education programs in other nations.

Administrators. The success of any program depends on visionary leadership. Administrators must endeavor to provide all the necessary resources and support needed to run effective distance education program. Administrators should see themselves as resource providers and must design plan and strategy for success.

Technology department. Distance learning programs must make provisions for technology departments to help in trouble shooting any technical challenge that may arise. To avoid high costs associated with large technology departments, students and site facilitators could be trained to handle minor technical issues, and issues beyond their expertise would then be referred to advanced personnel.

Teacher support. Teachers should receive adequate support through training and mentorship as they learn the technology or delivery media employed in this kind of learning environment. This will help alleviate fear and/or anxiety and boost teacher confidence. Confidence boosting will attract more teachers to 
teach in this kind of environment and at the same time, encourage those who are already participating in the program to stay.

Encouragement of interaction/social presence. Students should have the opportunity to engage in service learning and community building activities as a way to ensure social interaction. This could be done through field trips, collaborative assignments/projects and online social networking features like Face book, Skype, Yahoo Messenger etc.

Interaction: Interaction between student-teacher and studentstudent should be a top priority in this kind of educational environment. Irrespective of the delivery mode-either synchronous or asynchronous - interaction should be a key in bridging the transactional distance between the instructor and student.

Funding. Distance education operating institutions should not depend on one source of income, such as tuition. Program developers and administrators should seek out other sources of income for regularity and sustainability to keep the program viable.

Student orientation. Instructors should offer orientation/basic training to incoming students on the technology and delivery medium prior to beginning their distance education experience. This will help students gain familiarity and confidence prior to engaging in this new way of learning.

Parental support. School staff should encourage parents to support their child or ward as they embark and continue on in their education in distance learning environment. Educators should provide parents with opportunities to learn about how they can best support their children's success in distance learning.

\section{References}

Chamez, K. (2003). Grounded theory. In J. A. Smith (Ed.), Qualitative psychology: A practical guide to research methods (pp. 81-110).
London: SAGE.

Creswell, J. W. (2007). Qualitative inquiry and research design: Choosing among five approaches. Thousand Oaks, CA: Sage.

Davies, M. B. (2007). Doing a successful reseacrh project using qualitative or quantitative methods. New York, NY: Palgrave Macmillan.

Eisner, E. W. (1991). The enlightened eye: Qualitative inquiry and the enhancement of educational practice. New York, NY: Macmillan.

Flick, U. (2007). Managing quality in qualitative research. Thousand Oaks, CA: Sage.

Freed, K. J. (2003). A history of distance learning: Interactive distance learning. Media Visions Journal. URL (last checked 10 March 2010) http://www.media-visions.com/index.htm

Gillis, M. (1999). In higher education in developing countries: Peril and promise, 2000. Washington, DC: World Bank.

Giorgi, A., \& Giorgi, B. (2003). Phenomenology. In J. A. Smith (Ed.), Qualitative psychology: A practical guide to research methods (pp. 20-25). London: SAGE.

Harber, C. (2010). Education and theories of development. In: E. Lemmer and N. van Wyk (Eds). Themes in South African education. Cape Town: Pearson.

Huberman, A. M., \& Miles, M. B. (2002). The qualitative researcher's companion. Thousand Oaks, CA: Sage.

Maso, I. (2001). Phenomenology and ethnography. In P. Atkinson, A. Coffey, S. Delamont, J. Lofland and L. Lofland (Eds.), Handbook of ethnography (pp. 136-144). London: SAGE.

Nava, A., Fischer, K., Bruer, J. T., Bransford, J., Brown, A. L., Caviness, L. D., Arvidson, M., \& Immording-Yang, M. H. (2007). Critical issues in brain science and pedagogy. Burr Ridge, IL: McGraw Hill.

Phillips, D., \& Schweisfurth, M. (2007). Comparative and international education: An Introduction to theory, method and practice. London: Continuum.

The Task Force (2000). Higher education in developing countries: Peril and promise. Washington, DC: The World Bank. 